Received Date : 06-Aug-2015

Revised Date : 23-Nov-2015

Accepted Date : 28-Dec-2015

Article type : Original Research: Empirical research - qualitative

$$
\square
$$<smiles>C1CCC1</smiles>

\title{
A qualitative study of the barriers and enablers to fertility-awareness education in general
} practice

Running head: A primary care model in fertility-awareness

\section{Authors and their affiliations:}

Dr Kerry D HAMPTON ${ }^{1}, \mathrm{RN}, \mathrm{RM}, \mathrm{PhD}$

A/Prof Jennifer M NEWTON ${ }^{2}, \mathrm{RN}$, EdD, Grad Cert Sci

A/Prof Rhian PARKER ${ }^{3}$, B.Sc, M.Sc, PhD

Prof Danielle MAZZA ${ }^{1}$, MD, MBBS, FRACGP

1. Department of General Practice, Monash University

2. School of Nursing and Midwifery, Monash University

3. Centre for Research and Action in Public Health, University of Canberra

Acknowledgements: We thank the general practitioners and practice nurses who participated in this study and Judith Greaves for her research support.

Conflicts of interest: None. The funders played no role in the study design, analysis, interpretation of results, or recommendations for practice.

Funding: The authors wish to acknowledge the 2012 Mid-Year "Babe" Norman Scholarship (Rosemary Norman Foundation and Nurses Memorial Centre), 2011 Family Medical Care, Education and Research Grant (Royal Australian College of General Practitioners, National Research Awards), and 2011 ANF

This is the author manuscript accepted for publication and has undergone full peer review but has not been through the copyediting, typesetting, pagination and proofreading process, which may lead to differences between this version and the Version of Record. Please cite this article as doi: $\underline{10.1111 / j a n .12931}$

This article is protected by copyright. All rights reserved 
Annual Higher Education and Research Grant (Australian Nursing Federation, Vic Branch) that assisted this project.

Word count: abstract $=243 ;$ main text $=4634 ;$ tables $=2 ;$ references $=31$.

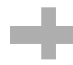

Corresponding author: Dr Kerry Hampton, 'Monash University, Building 1, 270 Ferntree Gully Road, Notting Hill, Victoria, Australia 3168; P: 6139830 5280; E: kerry.hampton@ monash.edu.

Twitter username: @ dr_kerryhampton

\section{ABSTRACT}

Aims: To understand the barriers and enablers to fertility-awareness education in general practice.

Background: Most women along with their primary care practitioners - general practitioners and practice nurses - believe that women should be educated about fertility-awareness when first reporting trouble conceiving. To date, no in-depth study has examined the enablers and challenges of this type of education in general practice.

Design: A descriptive exploratory qualitative study using deductive content analysis.

Methods: General practitioners $(N=11)$ and practice nurses $(N=20)$ were recruited from general practices in three socio-culturally diverse areas in Victoria, Australia. Data were collected through semi-structured interviews based on the 12 domains of a theoretical behaviour change framework from April-August 2012. The participants' responses were organized into themes that fall under the framework domains.

Findings: The biggest barriers to fertility-awareness education in general practice were short consultations and time constraints faced by general practitioners together with a lack of patient educational materials and remuneration to support its delivery. The biggest enablers were a greater use of nurses trained in fertility-awareness in a collaborative team care arrangement with general practitioners.

Conclusion: This study has identified several important barriers and enablers to fertilityawareness education in general practice. Translation into practice of our findings is imperative as This article is protected by copyright. All rights reserved 
the first step in establishing a primary care model in fertility-awareness. This would fill an important gap in the primary care of infertile women and build capacity in general practice to reduce infertility through women's enhanced fertility-awareness.

Keywords: infertility, general practice, fertility-awareness, nursing, midwifery, family planning, primary care

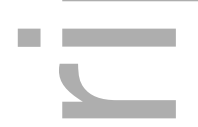

\section{Why is this research needed?}

- The fertile period of the menstrual cycle is poorly understood by most women.

- General practitioners and practice nurses agree that women's fertility-awareness should be enhanced in general practice when first reporting trouble conceiving.

- Nurses have been nominated as the most preferred practitioners to deliver fertility-awareness education in general practice, but effective models of multidisciplinary care in fertilityawareness are yet to be described.

\section{What are the key findings?}

- Greater use of nurses in a collaborative team care arrangement with general practitioners is needed to improve the delivery of fertility-awareness education in general practice.

- General practitioners and practice nurses need specific education to improve their knowledge, skills' confidence in fertility-awareness.

- Patient educational materials and remuneration are needed to support the delivery of fertilityawareness education in general practice.

\section{How should the findings be used to influenced policy/practice/ research and education?}

- The findings should be used to develop an interdisciplinary program of education on fertilityawareness for general practitioners and practice nurses.

- The findings should be used to expand scope of practice and increase career pathways for nurses in general practice.

This article is protected by copyright. All rights reserved 
- Healthcare policies need to reflect interdisciplinary primary care models in fertilityawareness to increase women's chances of spontaneous conception.

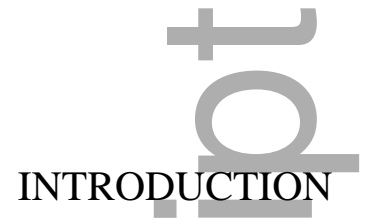

Infertility is a global public health issue that affects around 9\% of couples (The World Health Organization 2008, Boivin et al. 2009). Many studies have concluded that women's poor understanding of the fertile period of the menstrual cycle (called fertility-awareness) should be addressed in primary care as one way of reducing infertility (Hampton et al. 2012, Bunting et al. 2013, Hammarberg et al. 2013, Lundsberg et al. 2014, Hampton and Mazza 2015). However, the barriers and enablers of this type of education in general practice have not previously been described. We, therefore, used semi-structured interviews guided by a theoretical behaviour change framework to obtain the views general practitioners (GPs) and practice nurses (PNs) working in diverse general practices.

\section{Background}

GPs (also known as primary care or family physicians in some countries) are ideally placed in the healthcare system to play a role in both prevention and treatment of infertility. Yet, fewer women are receiving this type of care in general practice as a result of increasing referrals to assisted reproductive technology (ART) clinics (Wilkes et al. 2007, Britt et al. 2011). However, ART conceived children compared with naturally conceived children are associated with higher overall healthcare costs and increases in morbidity and mortality for both mothers and children (Kamphuis et al. 2014).

To increase prevention in healthcare and help reduce the general trend towards specialist healthcare, many countries now emphasise primary health care (PHC) (The World Health Organization 2008). PHC is a rights based approach to healthcare for all in their community, achieved primarily through comprehensive service delivery in new primary care models This article is protected by copyright. All rights reserved 
promoting health literacy (The World Health Organization 2008). Person-centred care, prevention in healthcare, and equity in healthcare are key features of PHC (The World Health Organization 2008). General practice has been identified as a key area for change to embed PHC and, consequently, it is evolving to reflect the aforementioned principles (Hoare et al. 2009, Hoare et al. 2011).

The inclusion of nurses in the general practice workforce (called PNs in Australia) has occurred only in the last few decades and, to date, their current scope of practice is limited (Hoare et al. 2011). However, expanding the scope of practice and roles for nurses in general practice to better address the needs in their community is key to embedding PHC in health systems (Halcomb et al. 2006, Hoare et al. 2011). Systematic reviews indicate that patient education and counselling contribute to lifestyle change for primary prevention of disease and that nurses are effective in the delivery of such interventions (Laurant et al. 2007, Harris et al. 2009). Patients have reported that they would be as likely to adopt positive health behaviours whether it was recommended by a PN or a GP, and that they perceive PNs to be more approachable and understanding when discussing lifestyle factors (Mitchell et al. 2011).

This qualitative paper reports the findings of the second phase of our four-year fertilityawareness study that sought to inform the development of a future primary care model in fertility-awareness. In the first phase, we established that poor levels of fertility-awareness exist in women, yet most women would like to receive this type of education before they are referred to ART clinics (Hampton 2014). Change in contemporary general practice offers the opportunity to deliver fertility-awareness education, but little is known about the barriers and enablers and how GPs and PNs can best work together to enhance the fertility-awareness of women who report trouble conceiving. We, therefore, used a theoretical behaviour change framework to assist the translation of our research findings into clinical practice.

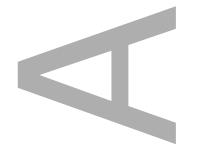

This article is protected by copyright. All rights reserved 


\section{THE STUDY}

\section{Aim}

The aim of the study was to understand the barriers and enablers to fertility-awareness education in general practice from the perspectives of GPs and PNs.

\section{Design}

This phase of a larger study sought to inform the development of a future primary care model to improve the delivery of fertility-awareness education in general practice. Understanding the clinical practice setting is critical to the successful translation of research findings into clinical practice (Michie et al. 2005). We, therefore, used Michie et al.'s (2005) theoretical domain framework (Table 1) in this qualitative phase, as the framework aims to improve implementation of evidence-based practice by capturing in a systematic way the full range of mechanisms (barriers and enablers) that may be involved in professional behaviour change (Michie et al. 2005).

\section{Participants}

To obtain the views of GPs and PNs that reflected diverse general practices, purposeful sampling was conducted in three different Divisions of General Practice (DGP) (a regional network of general practices) in Victoria, Australia (PCHRIS 2012). The outer metropolitan DGP compared

with the inner metropolitan DGP in a major city in Australia was located in a socio-economically disadvantaged area in terms of household income, education, occupation, and the proportion of non-English speaking background people. The rural DGP was located in a mid-range area (Australian Bureau of Statistics 2008).

GPs and PNs were invited to participate in this study through advertisements in newsletters of the targeted DGP and by faxing invitations directly to practices in these divisions. Individual telephone interviews were conducted with GPs as they can be difficult to recruit into focus groups (Bajramovic et al. 2004), and focus groups were conducted with PNs for the benefits that 
group interviews can afford (Kitzinger 1995). A total of 31 participants, GPs $(N=11)$ and PNs $(N=20)$, agreed to participate in this study.

\section{Data collection}

A total of 11 individual telephone interviews with GPs and three focus groups with PNs $(N=20$ in 3 focus groups with 5 to 8 participants in each group) were conducted between April-August 2012. To maintain consistency, all interviews and focus groups were conducted by the same facilitator $(\mathrm{KH})$ and the schedule of questions used in all was the same. The questions were based on the 12 domains of Michie et al.'s (2005) theoretical framework and refined according to the findings of our previous research (Hampton 2014). The interviews were approximately 20 minutes in duration and the focus groups were approximately 90 minutes in duration. All were audio-recorded, and each participant received a \$75.00 gift voucher in appreciation of their time.

\section{Ethical considerations}

This study was approved by a university and informed consent was obtained from all participants who were assigned codes for confidentially.

\section{Data analysis}

The verbatim text data were independently analyzed by the first two authors $(\mathrm{KH}, \mathrm{JN})$. To familiarize themselves with the text data, all transcripts were read twice. Using a deductive process of thematic analysis (Hsieh and Shannon 2005), the text data were searched for key concepts and patterns in relation to the research questions. Initial 'code names' were applied, and these were later categorized according to the domains in Michie et al.'s (2005) theoretical framework (Table 1). All codes related to at least one domain and several codes related to more than one domain, thus, highlighting, an overlap of content in several of the domains in this study. This dilemma and any other disputes in the coding were resolved through discussion and agreement. The coded data were then imported into NVivo 9 software (QSR International Pty Ltd. 2010) and under their assigned domains organized into themes and sub-themes. In this step, both between and within group analysis (Shih 1998) was conducted.

This article is protected by copyright. All rights reserved 


\section{Validity and reliability}

Michie et al.'s (2005) theoretical framework is a validated tool that has been used in several health contexts to understand the barriers and enablers to evidence-based practice (Mazza et al. 2014). The schedule of questions was based on the domains of Michie et al.'s (2005) framework, refined according to our research findings leading up to this qualitative phase (Hampton 2014), then piloted in a focus group $(N=3)$ resulting in only minor changes. In coding the data, we followed the accepted steps of deductive content analysis (Hsieh and Shannon 2005). All code names, themes and sub-themes that fall under the domains were arrived at through discussion and consensus between the first two authors (KH, JN).

\section{FINDINGS}

The GPs $(N=11)$ in this study comprised of four men and six women. All of the PNs $(N=20)$ were women. The socio-demographic characteristics of the study participants across the three DGPs were fairly even (Table 2).

Deductive content analysis revealed six themes and three sub-themes that influence fertilityawareness education in general practice: (1) lack of everyday resources, (2) belief in preventive healthcare, (3), lack of skills (4) practice options for fertility-awareness education, (5) medical dominance, and (6) the personal nature of the topic. These are discussed below in accordance with the seven domains they fall under in Michie et al.'s (2005) theoretical framework.

\section{Theme 1: Lack of everyday resources}

There was a consensus among GPs and PNs that resources such as a lack of time, patient educational materials and remuneration, were major barriers to fertility-awareness education in general practice. These sub-themes, presented as follows, reflect Michie et al.'s (2005) domain of environmental context and resources (Domain 8).

\section{Sub-theme 1.1: Lack of time}

Short consultations made it difficult for GPs to raise the topic of fertility-awareness with their female patients or to provide anything other than basic instruction when the information was This article is protected by copyright. All rights reserved 
specifically requested. In addition, they said that women typically did not make appointments specifically for fertility-awareness, but instead sought it out in the context of other consultations when no time was available, as illustrated in the excerpt below:

Often you have only 10 or 15 minutes and the fertility issue is a very complex area so 15 minutes is not enough to cover very much, and a lot of the time patients don't have the time. They come in with a list of things or they're in a hurry. (Female GP, Low SES area)

The preconception health check was considered the ideal time to raise the topic of fertilityawareness with women. This was considered especially important when other known risk factors for infertility were present. However, identified barriers to this approach were that many women did not to attend the preconception health check and that the preconception health check is already oversubscribed, as the following participants shared:

If women were aware that they needed to come in for a health check before actively trying that would provide an opportunity to discuss this kind of thing [fertility-awareness]. (Female GP, High SES area)

In the pre-conception health check, there is so much to cover...it's hard to fit it all in. (Female GP, High SES area)

Short consultations together with the belief that fertility-awareness education was timeconsuming led several GPs to suggest that this type of education was typically provided only when specifically requested, as illustrated below:

I would say your average GP would wait until the topic's brought up, because they're busy, he hasn't got the time to initiate the conversation...(Female GP, High SES area)

PNs echoed the views of GPs in this theme, adding that they believed short GP consultations were contributing to the premature referral of infertile women to specialists, as the following interview excerpt highlights:

This article is protected by copyright. All rights reserved 
My doctors disappoint me by just shuffling people off to IVF specialists when you know they don't understand... when they are fertile...It disappoints me because...some people just need that education and the doctor just doesn't have the time to do that in his 10-minute consultation. (PN, High SES area)

\section{Sub-theme 1.2: Lack of patient educational materials}

A lack of patient educational materials was the second most frequently discussed environmental barrier to fertility-awareness education in general practice. For these materials to be kept up-todate and be readily available, it was suggested that they are kept in a central location (i.e. downloadable from their computer). GPs and PNs believed that up-to-date and readily available patient educational materials were critical to delivering fertility-awareness education with confidence, as they shared in the excerpts below:

One thing that may help increase confidence is having appropriate written material so I could read, work through the written material and then give that to patients. (Female GP, Low SES area)

It's a big discussion and people may not remember everything that's said. So if you can discuss it and then give people something to take away they can read and reinforce and refer to, I think that's ideal. (Female GP, Low SES area)

\section{Sub-theme 1.3: Lack of remuneration}

General practices were characterized as small businesses that were entirely dependent on income generating tasks for their sustainability. A lack of remuneration for fertility-awareness education was therefore considered a major barrier to its delivery, as the following illustrate:

Remuneration is important because of the way general practice is structured. (Female GP, Low SES area)

Unless there's somebody there that's got an interest, a real interest [then] it gets swept under the carpet...because there doesn't seem to be the money to be made out of that area. (PN, Rural area)

This article is protected by copyright. All rights reserved 
In this theme, PNs believed that GPs' consultation fees were a barrier to fertility-awareness education in general practice, and suggested:

Affordability is an issue for a lot of our patients. (PN, High SES area)

Our doctors are very strict on their appointment time and will say, look I'm sorry, I can't discuss that with you. You need to make another appointment. Make a double appointment next time. But I think sometimes that might have put them off of wanting to come back. (PN, High SES area)

Despite these barriers, the utility of enhancing women's fertility-awareness in general practice was generally appreciated.

\section{Theme 2: Belief in preventive healthcare}

Prevention in healthcare was discussed as a critical function of general practice. This theme reflects Michie et al.'s (2005) domain of social/professional role and identity (Self-Standards) (Domain 3) and centres on the participants belief that they have a professional role and responsibility in promoting preventive healthcare. Women GPs and PNs, in particular, stressed that enhancing women's fertility-awareness in general practice was one way of optimizing natural conception and reducing unnecessary referrals for ART treatment, as the following interview quotes highlight:

We need to be able to tell patients when to have more intercourse...It's not always that they need to go down the IVF pathway. (Female GP, Low SES area)

There's lots of self-management in general practice now and there's no reason why that can't be translated into women's health. (PN, Rural area)

Notwithstanding these generally positive attitudes to fertility-awareness, neither GPs nor PNs felt skilled enough to deliver fertility-awareness education in any comprehensive way.

This article is protected by copyright. All rights reserved 


\section{Theme 3: Lack of skills}

This theme centres on the participants concern that they do not have the necessary knowledge or skills to instruct women in fertility-awareness because of a lack of education and training in their under- and post-graduate courses. These concerns reflect Michie et al.'s (2005) domains of knowledge (Domain 1) and skills (Domain 2) and highlight the need for professional development among GPs and PNs in this field of clinical practice. Their general lack of preparedness is captured in the quotes below:

They [GPs] need the knowledge to give the right advice...it's not something that you really get much education about. (Female GP, High SES area)

I'm not confident in the subject. My knowledge around fertility is pretty minimal. (PN, Rural area)

The women GPs, in particular, shared that they have sufficient knowledge only to provide basic instruction in fertility-awareness and if any detailed information was required they indicated that this was beyond their skill level, as illustrated in the quotes below:

I think I can provide some [fertility-awareness education] but if I was to do it properly I would probably need to do a refresher course. (Female GP, Low SES area)

I feel confident enough that I could provide the basic first steps and if it gets more complicated... have been referring my patients to a gynaecologist. (Female GP, High SES area)

Only one of the five men GPs offered fertility-awareness education, most believed they were inadequately qualified, as illustrated in the excerpts below:

The GP themselves feeling that they don't have the knowledge to provide that type of advice or counselling, so they're not going to launch in on it because they don't feel confident themselves. (Male GP, Rural area)

This article is protected by copyright. All rights reserved 
Barriers to providing that advice would be not being qualified. For instance, if I referred them to IVF programs...I know that they're going to get quality advice right up to the point of intervention and conceiving. (Male GP, High SES area)

Without exception, PNs shared that they did not provide fertility-awareness education as it did not fall into their current scope of practice, as highlighted in this PN's comment:

You can't presume that nurses have education on this subject. (PN, High SES area)

When GPs and PNs were asked about what mechanisms could be put in place to assist in the delivery of fertility-awareness education for women in general practice, several practice options were suggested, as the next theme shows.

\section{Theme 4: Practice options for fertility-awareness education}

GPs and PNs agree that the single most important enabler of fertility-awareness education in general practice is credentialed nurses in fertility-awareness who work in a collaborative team care arrangement with GPs. This theme reflects Michie et al.'s (2005) domain of behavioural regulation (Domain 11) and centres on the participants belief that specially trained nurses in fertility-awareness in a clearly defined pathway of care with GPs is essential to improve the delivery of fertility-awareness education for women in general practice, as encapsulated in the participant's voices:

I think dedicated nursing staff are needed to explain this sort of thing...you need to have a staff member who can sit down for 20 minutes, half an hour and just explain carefully what it is that you want patients to understand. (PN, High SES area)

It's like diabetes is now considered multidisciplinary care so I think fertility should start to come into that area. (Female GP, Low SES area)

This article is protected by copyright. All rights reserved 
In practices where demand is low, a visiting fertility nurse specialist and referral pathways to local well women's health clinics were suggested as alternative practice options, as the following quotes highlight:

In our clinic, we have visiting diabetic nurses and visiting asthma nurses...so having visiting fertility nurses is another way of bringing it into the general practice arena. (PN, High SES area)

In a busy general practice, you don't have the time to get bogged down in laborious conversations if it's not your field...you need to be a good delegator. (PN, Rural area)

PNs believed that this type of education should fall within their scope of practice and being a highly feminized profession this would help bridge several barriers to the education, as illustrated below:

Fertility-awareness education is something that we should be able to deal with (PN, Rural area)

If the doctors don't feel comfortable talking about fertility-awareness with their patients...if there's a female nurse...p patients might feel more comfortable and the doctor might feel like they've been able to provide the advice without doing it personally. (PN, High SES area)

GPs believed that nurses appropriately trained in fertility-awareness were essential for them to have a confidence in referring women to PNs and, similarly, PNs believed that they would be well used by GPs if GPs knew they were appropriately qualified, as participants voiced:

It's a matter of making sure [the] Practice Nurse has accurate, up to date information...then allowing them to venture into that area of advice and counselling. (Male GP, Rural area)

I think if you educate nurses like...online training...like a certificate... [and] once the doctor knows that the nurse is trained, they'll often utilize the nurse for the education. (PN, High SES area)

This article is protected by copyright. All rights reserved 
It seems that the lack of primary care interventions in general practice addressing infertility has contributed to the increasing referral rates for ART treatment, as the following theme highlights.

\section{Theme 5: Medical dominance}

GPs and PNs spoke of ART as the main treatment option for infertility. This theme reflects 'decision processes' in Michie et al.'s (2005) domain of memory, attention' decision processes (Domain 7). It centres on the fact that no primary care model currently exists in general practice to reduce infertility and, conversely, that systems are well established for referring infertile people to ART clinics. Direct marketing in general practices by ART services encouraging early referrals was believed to further exacerbate this problem, as the following quotes illustrate:

IVF come and do a lunch and they tell the GPs... what their success rate is....and the GP's are

told: if a couple's been trying for six months and nothing's happening, refer them straight away...That's the standard practice now and has been for well over 12 months. (PN, High SES area)

I've noticed the GP used to keep the patient in the clinic and educate them more roundly on lots of things, but now we send them off to specialists. (PN, Low SES area)

The personal nature of fertility-awareness was also considered a major barrier to fertilityawareness education in general practice.

\section{Theme 6: The personal nature of the topic}

Fertility-awareness is highly personal in nature and, consequently, this 'nature' was considered an important barrier to fertility-awareness education in general practice. This theme reflects Michie et al.'s (2005) domain of emotion (Domains 10). It centres on participants beliefs that some GPs may not feel comfortable raising fertility-awareness with their female patients. Whilst, conversely, some women may not feel comfortable seeking the information out from their GP. This particular barrier was considered an even greater barrier in the presence of difference (e.g., 
gender, language, culture, and religious), which PNs by virtue of being a highly feminized healthcare workforce believed they could help overcome, as encapsulated in the quotes below:

One of our doctors doesn't feel comfortable doing Pap Smears, so he would possibly feel uncomfortable talking about it [fertility-awareness]. (PN, High SES area)

The doctors in our practice have different cultural backgrounds. So I think that is a barrier to them discussing [fertility-awareness]...they're very strongly religious. (PN, Low SES area)

The fact that nurses are women helps. That's why nurses are probably better at this conversation. They don't even blink about talking about mucus and menstruating. But I think men really don't want to go there. (PN, High SES area)

\section{DISCUSSION}

Using a theoretical behaviour change framework, we identified several important barriers and enablers to fertility-awareness education in general practice. The biggest barriers were time constraints faced by GPs together with a lack patient educational materials and remuneration to support its delivery. The biggest enablers were a greater use of nurses trained in fertilityawareness who work in a collaborative team care arrangement with GPs. These findings help to explain women's low levels of knowledge of fertility-awareness found in the first phase of our study (Hampton et al. 2012, Hampton and Mazza 2015), and will assist in the translation of our study findings into a future primary care model.

In addition, this qualitative phase confirms several findings in our GP and PN survey (Hampton 2014). First, GPs and PNs are generally aware of women's limited fertility knowledge and agree that an educational intervention enhancing women's fertility-awareness may help some infertile couples to conceive. Second, a high degree of agreement exists among GPs and PNs that nurses are the most preferred practitioners to deliver fertility-awareness education for women in general practice. The main factors that informed this belief were that fertility-awareness education is generally time-consuming (Kelly et al. 2012), PNs are better positioned than GPs are to spend more time with patients (Bekaert 2003), and being a highly feminized healthcare workforce, this This article is protected by copyright. All rights reserved 
would make it easier for women to raise sexual health issues (Mills et al. 2012) and, similarly, to receive fertility-awareness instructions. Greater use of PNs has been found to improve women's healthcare in other sexual health contexts in general practice (Mills et al. 2012).

Our study shows a willingness among GPs, especially women GPs, to relinquish fertilityawareness education to PNs and also a desire among PNs to take up a new role in this clinical field (Hampton 2014). The agreed nature of this suggested change in practice (Mills et al. 2012) together with the belief that enhancing women's fertility-awareness can improve health outcomes are key enablers of expanded practice roles for nurses in general practice (Ehrlich et al. 2013).

In recognition of the fact that nurses and midwives are not typically trained in fertility-awareness (Fehring 2004), both GPs and PNs believe that nurses and midwives need to undergo specific training. This was considered essential both for quality assurance in patient outcomes (Fehring 2004) and for effective team care management. GPs and PNs believe the education should be to the minimum level of a certificate course and ideally delivered online to help reduce traditional barriers to professional development (i.e., cost, time, convenience and geographic location) (Parker et al. 2011). In addition, patient education materials are needed to assist in the delivery of fertility-awareness education for women (Kelly et al. 2012). These materials should be evidence-informed, concise and readily available from a central location (i.e., downloadable from their computer). They should also be culturally appropriate to meet the needs of women from different cultural groups (Kelly et al. 2012).

Although new funding for care services by PNs has been available in Australia since January 2012 (Department of Health and Ageing 2012), no GP or PN in our study indicated awareness of this enhanced funding arrangement from which PNs could be drawn on to deliver care services such as fertility-awareness education. Whilst our study shows that awareness of this new funding arrangement needs to be increased among Australian GPs and PNs, internationally the most suitable funding model to promote care services by PNs nurses remains contentious (Hoare et al. 2009).

This article is protected by copyright. All rights reserved 
A coordinated team care approach to enhancing women's fertility-awareness in the preconception health check would greatly improve the timeliness, accessibility and affordability of this intervention, with the added benefit of easing time pressures on female GPs who currently provide the bulk of women's healthcare in general practice (Mills et al. 2012). This approach would optimise the benefit of this intervention, especially when other risk factors for infertility are present, such as advanced maternal age and being overweight or obese. For women who do not attend the preconception health check (around half) (Callaway et al. 2009), the intervention should then be delivered opportunistically when women first report trouble conceiving.

Our study sought to inform a new primary care model in fertility-awareness. We have described how GPs and PNs can best work together to enhance women's fertility-awareness as one way of reducing infertility in general practice, and that nurse training in fertility-awareness, patient educational materials and funding are needed to support its delivery. Expanded practice roles for nurses in fertility-awareness would optimise women's access to this intervention and promote and health equity, especially among rural people and other disadvantaged groups (Commonwealth of Australia 2010, Utting et al. 2012). Change will, however, require a major cultural shift in the GP/PN relationship as only $8 \%$ of preventive healthcare activities in Australian general practices involve a PN (Britt et al. 2011).

\section{Limitations and strength}

Even though the theoretical behaviour framework we used was comprehensive, it may not have captured all the barriers and enablers to fertility-awareness education in general practice. The relatively small sample that was recruited from only one state in Australia may reduce the transferability of the findings to national and international contexts. The views of the GPs and PNs who volunteered to participate in this study may differ from those who chose not to participate. In addition, most participants were women, which may have influenced our study findings. Despite these limitations, there was general agreement among GPs and PNs across all three targeted DGP represented in this study about the main barriers and enablers to fertilityawareness education in general practice. Another strength is the inclusion of practices with high This article is protected by copyright. All rights reserved 
immigrant and Australian Indigenous populations, which help strengthen the transferability of the study findings.

\section{Conclusions}

This study has identified several important barriers and enablers to fertility-awareness education in general practice. Translation into practice of our findings is imperative as the first step in promoting a primary care model in fertility-awareness. This would fill an important gap in the primary care of infertile women and build capacity in general practice to reduce infertility through women's enhanced fertility-awareness.

\section{Author Contributions:}

All authors have agreed on the final version and meet at least one of the following criteria (recommended by the ICMJE*):

1) substantial contributions to conception and design, acquisition of data, or analysis and interpretation of data;

2) drafting the article or revising it critically for important intellectual content.

* http://www.icmje.org/recommendations/

\section{References}

Bekaert, S. (2003). Improving healthcare provision for teenagers: Sarah Bekaert has been looking at ways to improve services for young people at her north London practice. Practice Nurse, 25(6), 38-45.

Boivin, J., Bunting, L., Collins, J. A. \& Nygren, K. G. (2009). Reply: International estimates on infertility prevalence and treatment seeking: potential need and demand for medical care. Human Reproduction, 24(9), 2380-2383. doi:10.1093/humrep/dep218

This article is protected by copyright. All rights reserved 
Britt, H., Miller, G. C., Charles, J., Henderson, J., Bayram, C., Valenti, L., Harrison, C., Pan, Y., O’ Halloran, J., Zhang, C., Chambers, T. \& Fahridin, S. 2011. A decade of Australian general practice activity 2001-02 to 2010-11. General practice series no. 30. Sydney: Sydney University Press.

Bunting, L., Tsibulsky, I. \& Boivin, J. (2013). Fertility knowledge and beliefs about fertility treatment: findings from the International Fertility Decision-making Study. Human Reproduction, 28(2), 385-397. doi:10.1093/humrep/des402

Callaway, L. K., O’callaghan, M. J. \& Mcintyre, D. H. (2009). Barriers to addressing overweight and obesity before conception. Medical Journal of Australia, 191(8), 425-428.

Commonwealth of Australia 2010. National Women's Health Policy. Canberra: Australian Government Department of Health and Aging,.

Department of Health and Ageing. 2012. The Practice Nurse Incentive Program [Online]. Australian Government. Available: http://www.health.gov.au/internet/main/publishing.nsf/Content/pnip [Accessed 12/07/2012].

Ehrlich, C., Kendall, E. \& St John, W. (2013). How does care coordination provided by registered nurses "fit" within the organisational processes and professional relationships in the general practice context? Collegian, 20, 127-135. doi:10.1016/j.colegn.2012.04.006

Fehring, R. J. (2004). The future of professional education in natural family planning. Journal of Obstetrics and Gynecological Neonatal Nursing, 33(1), 34-43. doi:10.1177/0884217503258549 Halcomb, E. J., Patterson, E. \& Davidson, P. M. (2006). Evolution of practice nursing in Australia. Journal of Advanced Nursing, 55(3), 376-388. doi:10.1111/j.13652648.2006.03908_1.X

Hammarberg, K., Setter, T., Norman, R. J., Holden, C. A., Michelmore, J. \& Johnson, L. (2013). Knowledge about factors that influence fertility among Australians of reproductive age: a population-based survey. Fertility and Sterility, 99(2), 502-507. doi:10.1016/j.fertnstert.2012.10.031

Hampton, K. D. 2014. Informing the development of a new model of care to improve the fertilityawareness of sub-fertile women in primary health care $\mathrm{PhD}$ Monash University

Hampton, K. D. \& Mazza, D. (2015). Fertility-awareness knowledge, attitudes and practices of women attending general practice. Australian Family Physician, 44(11), 840-845.

This article is protected by copyright. All rights reserved 
Hampton, K. D., Mazza, D. \& Newton, J. M. (2012). Fertility-awareness knowledge, attitudes and practices of women seeking fertility assistance Journal of Advanced Nursing, 69(5), 10761084. doi:10.1111/j.1365-2648.2012.06095.x.

Harris, M., Taggart, J., Williams, A., Dennis, S., Newall, A., Shortus, T., Denny-Wilson, E. \& Zwar, N. 2009. Effective Interventions to Improve Health Literacy in the Management of Lifestyle Risk Factors in Primary Health Care. Canberra: Australian Primary Health Care Research Institute (APHCRI) \& University of New South Wales.

Hoare, K. J., Fairhurst-Winstanley, W., Horsburgh, M. \& Mccormick, R. (2009). Nurse employment in primary care - UK and New Zealand. New Zealand Family Physician, 35(1), 28-31.

Hoare, K. J., Mills, J. \& Francis, K. (2011). The role of Government policy in supporting nurseled care in general practice in the United Kingdom, New Zealand and Australia: an adapted realist review. Journal of Advanced Nursing, 68(5), 963-980. doi:10.1111/j.13652648.2011.05870.x

Hsieh, H.-F. \& Shannon, S. E. (2005). Three Approaches to Qualitative Content Analysis. Qualitative Health Research, 15(9), 1277-1288. doi:10.1177/1049732305276687

Kamphuis, E. I., Bhattacharya, S., Van Der Veen, F., Mol, B. W. J. \& Templeton, A. (2014). Are we overusing IVF? British Medical Journal, 348(g252). doi:10.1136/bmj.g252

Kelly, P. J., Witt, J., Mcevers, K., Enriquez, M., Abshier, P., Vasquez, M. \& Mcgee, E. (2012). Clinician Perceptions of Providing Natural Family Planning Methods in Title X Funded Clinics. Journal of Midwifery \& Women's Health, 57(1), 35-42. doi:10.1111/j.15422011.2011.00107.x

Kitzinger, J. (1995). Qualitative Research: Introducing focus groups. British Medical Journal, 311(7000), 299-302.

Laurant, M., Reeves, D., Hermens, R., Braspenning, J., Grol, R. \& Sibbald, B. (2007). Substitution of doctors by nurses in primary care (Review). Cochrane Database of Systematic Revews, Issue 4. Art. No.: CD001271. DOI: 10.1002/14651858.CD001271.pub2., 1-37.

Lundsberg, L. S., Pal, L., Gariepy, A. M., Xu, X., Chu, M. C. \& Illuzzi, J. L. (2014). Knowledge, attitudes, and practices regarding conception and fertility: a population-based survey among

This article is protected by copyright. All rights reserved 
reproductive-age United States women. Fertility and Sterility, 101(3), 767-774. doi:10.1016/j.fertnstert.2013.12.006

Mazza, D., Petrovic, K., Grech, C. \& Harris, N. (2014). HPV vaccination in women aged 27 to 45years: what do general practitioners think? BioMed Central Women's Health, 14(1), 91. doi:10.1186/1472-6874-14-91

Michie, S., Johnston, M., Abraham, C., Lawton, R., Parker, D. \& Walker, A. (2005). Making psychological theory useful for implementing evidence based practice: a consensus approach. Quality and Safety in Health Care, 14(1), 26-33. doi:10.1136/qshc.2004.011155

Mills, J., Chamberlain-Salaun, J., Christie, L., Kingston, M., Gorman, E. \& Harvey, C. (2012). Australian nurses in general practice, enabling the provision of cervical screening and well women's health care services: a qualitative study. BioMed Central Nursing, 11(1), 23. doi:10.1186/1472-6955-11-23

Mitchell, L. J., Macdonald-Wicks, L. \& Capra, S. (2011). Nutrition advice in general practice: the role of general practitioners and practice nurses. Australian Journal of Primary Health, 17(2), 202-208. doi:10.1071/PY10101

Parker, R., Keleher, H. \& Forrest, L. (2011). The work, education and career pathways of nurses in Australian general practice. Australian Journal of Primary Health, 17(3), 227-232. doi:10.1071/PY10074

The World Health Organization 2008. The World Health Report 2008: Primary Health Care Now More Than Ever Geneva, Switzerland: World Health Organization.

Utting, S., Calcutt, C., Marsh, K. \& Doherty, P. 2012. Women and Sexual and Reproductive Health: Position Paper. Australian Women's Health Network Inc.

Wilkes, S., Hall, N., Crosland, A., Murdoch, A. \& Rubin, G. (2007). General practitioners' perceptions and attitudes to infertility management in primary care: focus group study. Journal of Evaluation in Clinical Practice, 13(3), 358-363. doi:10.1111/j.1365-2753.2006.00705.x

This article is protected by copyright. All rights reserved 
Table 1 Interview questions and the corresponding theoretical domains

\begin{tabular}{|c|c|}
\hline Domain & Interview questions \\
\hline Introductory questions & $\begin{array}{l}\text { - Can you tell me what you understand by the term 'fertility- } \\
\text { awareness'? } \\
\text { - What is your overall impression of the availability of } \\
\text { fertility-awareness education in general practice for women } \\
\text { who present with trouble conceiving? }\end{array}$ \\
\hline $\begin{array}{l}\text { Memory, att } \\
\text { decision pro }\end{array}$ & $\begin{array}{l}\text { What circumstances would prompt you to offer fertility- } \\
\text { awareness education to women who are having trouble } \\
\text { conceiving? } \\
\text { - Prompts: What about medical conditions, chronic diseases, } \\
\text { overweight, life circumstances, geographic circumstances, } \\
\text { financial situations, religious or cultural beliefs, male sub- } \\
\text { fertility }\end{array}$ \\
\hline $\begin{array}{l}\text { Beliefs about consequences } \\
\text { (Anticipated } \\
\text { outcomes/attitudes) }\end{array}$ & $\begin{array}{l}\text { - What do you consider are the benefits of fertility-awareness } \\
\text { education for women who are having trouble conceiving, } \\
\text { and what do you consider are the consequences when it is } \\
\text { not provided? }\end{array}$ \\
\hline $\begin{array}{l}\text { Environmental context and } \\
\text { resources (Environmental } \\
\text { constraints) }\end{array}$ & $\begin{array}{l}\text { - What factors in general practice do you consider make it } \\
\text { easier or difficult to provide fertility-awareness education } \\
\text { for women? }\end{array}$ \\
\hline $\begin{array}{l}\text { Social/profes } \\
\text { identity (Self }\end{array}$ & $\begin{array}{l}\text { - Nurses are increasingly being employed in general practice } \\
\text { and the roles of GPs and PNs are changing. How do you } \\
\text { envisage that GPs and PNs could work together to best } \\
\text { provide fertility-awareness education for women who are } \\
\text { having trouble conceiving? } \\
\text { - What factors would make a team-based approach difficult } \\
\text { and what factors would make it easier? }\end{array}$ \\
\hline
\end{tabular}

This article is protected by copyright. All rights reserved 


\begin{tabular}{|c|c|}
\hline $\begin{array}{l}\text { Beliefs about capabilities } \\
\text { (Self-efficacy) }\end{array}$ & $\begin{array}{l}\text { - Do you think you can provide this education? } \\
\text { - What factors reduce your confidence and what factors } \\
\text { would help improve it? }\end{array}$ \\
\hline Skills & $\begin{array}{l}\text { - What particular skills do you think GPs and PNs need to } \\
\text { provide fertility-awareness education for women who are } \\
\text { having trouble conceiving? } \\
\text { - What are the difficulties in providing this education and is } \\
\text { there anything that would make it easier? }\end{array}$ \\
\hline $\begin{array}{l}\text { Motivation and goals } \\
\text { (Intention) }\end{array}$ & $\begin{array}{l}\text { What do you consider are the main motivators among GPs } \\
\text { and PNs for providing fertility-awareness education for } \\
\text { women having trouble conceiving are? }\end{array}$ \\
\hline Social influ & $\begin{array}{l}\text { - To what extent do you consider culture of practice in } \\
\text { general practice facilitate or hinder practice in preventive } \\
\text { health care? } \\
\text { - What level of interest do you think women who are having } \\
\text { trouble conceiving have in fertility-awareness? }\end{array}$ \\
\hline Emotion & $\begin{array}{l}\text { - To what extent do you consider emotions of any kind among } \\
\text { GPs and PNs facilitate or hinder the provision of fertility- } \\
\text { awareness education for women who are having trouble } \\
\text { conceiving? } \\
\text { - How strongly do you feel about fertility-awareness } \\
\text { education for women who are having trouble conceiving? }\end{array}$ \\
\hline Knowledg & $\begin{array}{l}\text { What specific knowledge on the topic of fertility-awareness } \\
\text { do you consider GPs and PNs should have who provide this } \\
\text { education for women who are having trouble conceiving? }\end{array}$ \\
\hline Behavioural regulation & $\begin{array}{l}\text { - Are there are any procedures, preparatory step or routines } \\
\text { that could be put in place in general practice to better } \\
\text { facilitate fertility-awareness education for women who are } \\
\text { having trouble conceiving? }\end{array}$ \\
\hline
\end{tabular}

This article is protected by copyright. All rights reserved 


\begin{tabular}{|l|l|}
\hline Nature of the behaviours & $\begin{array}{l}\text { - What systems do you consider are needed in general } \\
\text { practice for maintaining the delivery of fertility-awareness } \\
\text { education for women? }\end{array}$ \\
\hline
\end{tabular}

Table 2 Socio-demographic characteristics of the participants according to area

\begin{tabular}{|l|l|l|}
\hline Description of area & $\begin{array}{l}\text { Participant numbers in } \\
\text { GP interviews (n=11) }\end{array}$ & $\begin{array}{l}\text { Participant numbers in PN } \\
\text { focus groups (n = 20, all } \\
\text { women) }\end{array}$ \\
\hline High SES & $4(2$ women, 2 men $)$ & 5 \\
\hline Low SES & $4(3$ women, 1 men $)$ & 7 \\
\hline Rural & $3(2$ women, 1 men $)$ & 8 \\
\hline
\end{tabular}

This article is protected by copyright. All rights reserved 


\section{University Library}

\section{- M M N E R VA A gateway to Melbourne's research publications}

Minerva Access is the Institutional Repository of The University of Melbourne

Author/s:

Hampton, KD;Newton, JM;Parker, R;Mazza, D

Title:

A qualitative study of the barriers and enablers to fertility-awareness education in general practice

Date:

2016-07-01

Citation:

Hampton, K. D., Newton, J. M., Parker, R. \& Mazza, D. (2016). A qualitative study of the barriers and enablers to fertility-awareness education in general practice. JOURNAL OF ADVANCED NURSING, 72 (7), pp.1541-1551. https://doi.org/10.1111/jan.12931.

Persistent Link:

http://hdl.handle.net/11343/291040 